\title{
Analysis on the Triaxial Shear Behavior and Microstructure of Cement-Stabilized Clay Reinforced with Glass Fibers
}

\author{
Bo Ruan $\mathbb{D}^{1},{ }^{1}$ Shilong Zheng $\left(\mathbb{D},{ }^{1}\right.$ Jidong Teng $\left(\mathbb{D},{ }^{2}\right.$ Hui Ding $\left(D,{ }^{1}\right.$ and Chao $\mathrm{Ma}^{3}$ \\ ${ }^{1}$ School of Civil Engineering, Central South University, Changsha 410075, China \\ ${ }^{2}$ National Engineering Laboratory for High-Speed-Railway Construction, Central South University, Changsha 410075, China \\ ${ }^{3}$ China Railway Siyuan Survey and Design Group Co., LTD, Wuhan 430063, China
}

Correspondence should be addressed to Jidong Teng; jdteng@csu.edu.cn

Received 31 July 2020; Revised 22 October 2020; Accepted 5 November 2020; Published 26 November 2020

Academic Editor: Jia-wen Zhou

Copyright (c) 2020 Bo Ruan et al. This is an open access article distributed under the Creative Commons Attribution License, which permits unrestricted use, distribution, and reproduction in any medium, provided the original work is properly cited.

\begin{abstract}
A series of triaxial compression tests were conducted to investigate the influence of the fiber content and confining pressure on the shearing characteristics of cement-stabilized clay reinforced with glass fibers. The glass fiber contents were $0,1 \%$, $2 \%$, $3 \%$, and $4 \%$ by weight of the dry soil. The stress strain and volume change behavior, shear strength, and energy absorption of the test specimen were obtained. The results indicate that the inclusion of glass fibers can increase the shear strength, inhibit the volumetric dilation of the test specimen, and improve its brittle behavior. The cohesion of the cement-stabilized clay reinforced with $4 \%$ glass fiber content is 2.8 times greater than that of the cement-stabilized clay. The effect of the fiber content on the friction angle is not obvious. It is found that the glass fiber reinforcement is more substantial under a low confining pressure. The scanning electron microscopy test results show that the surface of the glass fiber is wrapped with cement hydrate crystals, which increases the bite force and friction between the fiber and the soil particles. A single fiber is similar to an anchor in the soil, which enhances the mechanical properties of the cement-stabilized clay reinforced with fibers.
\end{abstract}

\section{Introduction}

Clay is widely distributed in southern China and has poor mechanical properties and poor water stability. According to the national criterion for high-speed railway design in China [1], clay belongs to group $C$ or group $D$, which cannot be directly used as the subgrade filling material of high-speed railways. The physical or chemical properties of clay should be improved before it is selected as a filling material in highspeed railway subgrades.

Cement is often added to the soil to improve its strength and water stability in engineering applications [2-4]. Cement-stabilized clay is used as a subgrade filling material in regions that lack high-quality subgrade filling materials. Moreover, cement-stabilized soil subgrade is considered an effective antifrost heave material and has been used in highspeed railway lines in cold regions [5-10]. For example, the subgrade surface layer of the Lanzhou-Xinjiang high-speed railway is composed of natural clay mixed with $5 \%$ cement
[11]. However, cement-stabilized soil has a relatively low tensile strength and low ductility $[12,13]$. Therefore, it is necessary to find a solution to improve the tensile strength and ductility of cement-stabilized soil.

At present, fibers are widely used as engineering materials in concrete to improve the tensile strength and ductility of concrete. Some scholars have also tried to add fibers to cement-stabilized soil, and studies have found that mixing discrete fibers with cement-stabilized soil can substantially improve the tensile strength, shear strength, residual strength, and ductility of cement-stabilized soil [14-17]. It has been found that the shear strength of cementstabilized soil reinforced with fibers increases with increasing fiber content, and longer fibers have a more obvious contribution to the strength of composites than short fibers $[18,19]$. Chen et al. $[20,21]$ found that the average strength enhancement increased and then decreased with the increase of the fiber length and the optimal fiber length is $6 \mathrm{~mm}$. Lovisa et al. [22] reported that the peak friction angle of 
cement-stabilized soil reinforced with fibers is the largest under wet conditions, while its cohesion reaches the largest value under dry conditions. There are other factors that can also affect the mechanical properties of cement-stabilized soil reinforced with fiber, such as the fiber type, fiber thickness, soil type, and cement content. [23-28].

However, there is still much controversy about the effects of fibers on cement-stabilized soil. Hamidi and Hooresfand [29] found that the incorporation of polypropylene fibers and glass fibers can reduce the initial stiffness of cement-stabilized soil and increase the cohesion and internal friction angle of cement-stabilized soil [30-32]. Consoli et al. [33-35] found that the initial stiffness of cement-stabilized soil was not affected by fibers, and both glass fibers and polyester fibers could reduce the cohesion of cement-stabilized soil and increase the friction angle. Kutanaei and Choobbasti [36] found that the incorporation of fibers increased the initial shrinkage behavior of cement-stabilized soil and reduced its residual expansion. In contrast, Fu et al. [37] found that there was no initial shrinkage behavior in cement-stabilized soil reinforced with fibers, and the incorporation of fibers could reduce the initial expansion and residual expansion. Ibraim and Fourmont [38] and Diambra et al. [39] found that cement-stabilized soil reinforced with fibers has a higher tendency to expand than cement-stabilized soil. It was evident from past studies that different scholars still had different views on the effects of fibers on the cohesion, internal friction angle, initial stiffness, and volumetric strain of cement-stabilized soil, and a consistent conclusion has not been reached. Therefore, further research is needed.

The objective of this study is to investigate the effect of the glass fiber content and confining pressure on the behavior of cement-stabilized soil. A series of laboratory tests will be introduced to measure the deviatoric stress-axial strain behavior, volumetric strain-axial strain behavior, deviatoric stress at failure, shear strength parameters, and energy absorption potential using consolidated drained triaxial compression tests. By conducting scanning electron microscopy (SEM) tests, the microstructure and the behavior of the interfaces between the glass fiber surface, clay particles, and cement hydrates are investigated to obtain a deep understanding of the mechanism of cement-stabilized soil reinforced with glass fibers.

\section{Materials and Methods}

2.1. Materials. Natural clay was used in these experiments, which was sampled from a high-speed railway construction site in Changsha, China. The sample was oven-dried and then crushed to pass through a $2 \mathrm{~mm}$ sieve. The soil properties are summarized in Table 1. Figures 1 and 2 show the photograph and the grain size distribution curve of the tested clay, respectively.

Ordinary Portland cement (Figure 3) is used as the cementing agent. The chemical composition of the cement is presented in Table 2 . The compressive strength of the cement mortar is $18 \mathrm{MPa}$ at 3 days and $45 \mathrm{MPa}$ at 28 days.
TABle 1: Physical and mechanical properties of the clay.

\begin{tabular}{lc}
\hline Soil properties & Values \\
\hline Specific gravity & 2.71 \\
Liquid limit (\%) & 40.8 \\
Plastic limit (\%) & 21.2 \\
Plasticity index & 19.6 \\
Optimum moisture content $(\%)$ & 17.2 \\
Maximum dry density $\left(\mathrm{g} / \mathrm{cm}^{3}\right)$ & 1.87 \\
Cohesive strength $(\mathrm{kPa})$ & 19.1 \\
Internal friction angle $\left({ }^{\circ}\right)$ & 27.5 \\
\hline
\end{tabular}

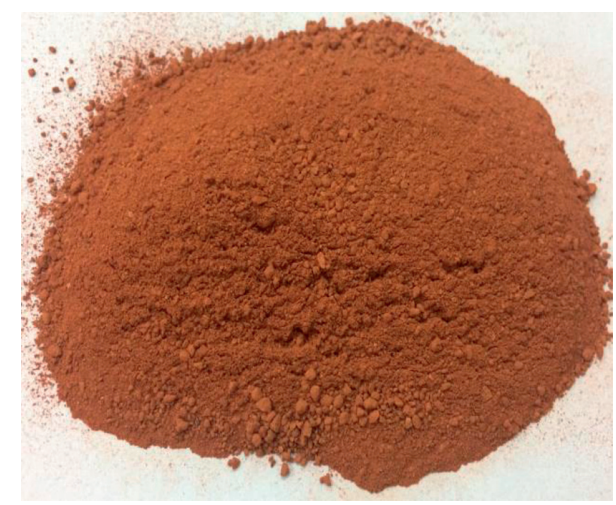

Figure 1: Tested soil.

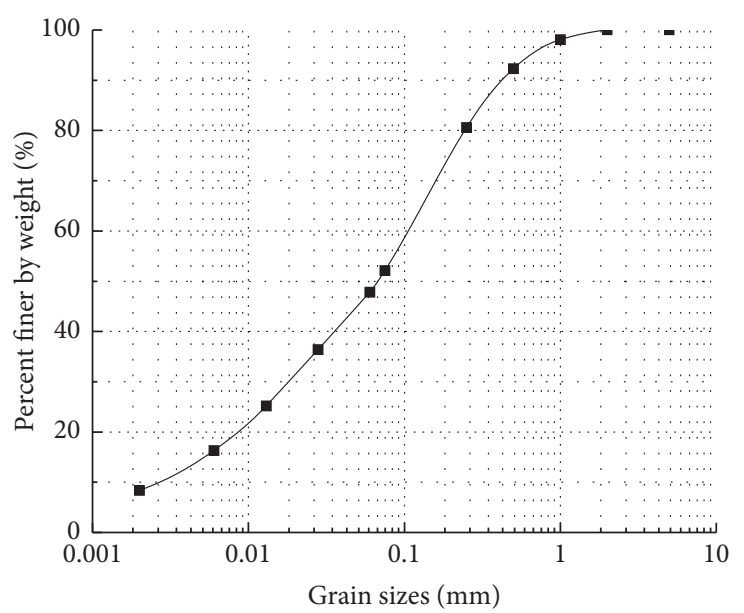

FIgURE 2: Grain size distribution of the tested soil.

The glass fiber (Figure 4) is chosen as the reinforcement material due to its excellent dispersity, high tensile strength, high elastic modulus, and environmentally friendly features. Some properties of the glass fibers provided by the manufacturer are given in Table 3.

2.2. Test Scheme. The fiber content is defined here as

$$
a_{f}=\frac{m_{f}}{m_{s}} \times 100 \%,
$$

where $m_{f}$ is the weight of the glass fiber and $m_{s}$ is the weight of oven-dried soil. 


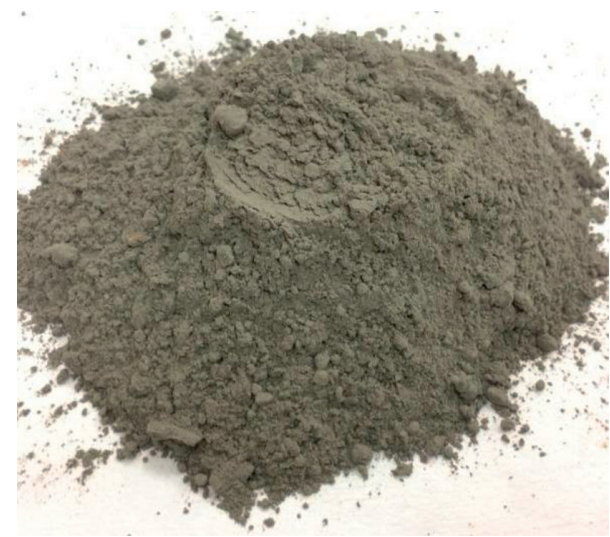

Figure 3: Portland cement.

TABle 2: Chemical composition of the cement.

\begin{tabular}{lc}
\hline Chemical constituent & Values (\%) \\
\hline $\mathrm{CaO}$ & 61.8 \\
$\mathrm{SiO}_{2}$ & 22.1 \\
$\mathrm{Al}_{2} \mathrm{O}_{3}$ & 4.7 \\
$\mathrm{Fe}_{2} \mathrm{O}_{3}$ & 3.8 \\
$\mathrm{SO}_{3}$ & 3.3 \\
$\mathrm{MgO}$ & 2.7 \\
$\mathrm{LOI}$ & 1.6 \\
\hline
\end{tabular}

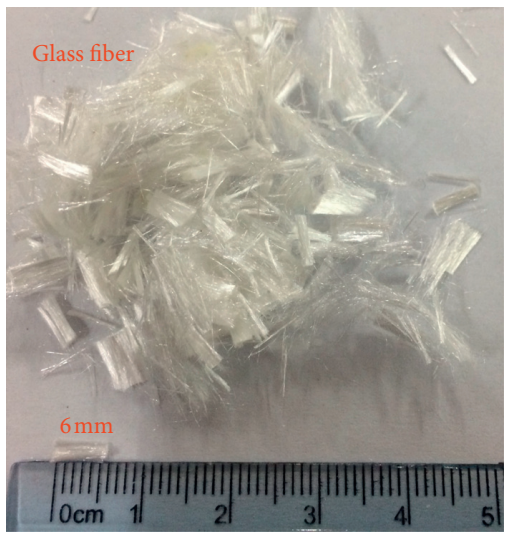

Figure 4: Photograph showing the discrete glass fibers.

TABle 3: Index of the glass fiber.

\begin{tabular}{lc}
\hline Behavior parameters & Values \\
\hline Fiber type & Single fiber \\
Average diameter $(\mu \mathrm{m})$ & 18 \\
Length $(\mathrm{mm})$ & 6 \\
Breaking tensile strength $(\mathrm{MPa})$ & 427 \\
Modulus of elasticity $(\mathrm{MPa})$ & 4102 \\
Fusion point $\left({ }^{\circ} \mathrm{C}\right)$ & 174 \\
Elongation at fracture $(\%)$ & 42 \\
Acid and alkali resistance & Good \\
Dispersibility & Excellent \\
\hline
\end{tabular}

Five different fiber contents are designed as $0,1 \%$, $2 \%$, $3 \%$, and $4 \%$. The fiber length is $6 \mathrm{~mm}$, the cement content (by weight of oven-dried soil) is $3 \%$, and the compaction coefficient (the ratio of dry density of samples to maximum dry density) is 0.95 . The fiber length and cement content are consistent with those in previous studies [20,21], such that it is possible to make comparisons with the previous results. The preliminary test shows that the maximum fiber content is $4 \%$, and when the fiber content exceeds $4 \%$, fibers can agglomerate together to form larger clusters during the preparation of specimens.

2.3. Preparation of the Specimens. Oven-dried clay and water were weighed according to the maximum dry density and optimum moisture content, and then they were mixed evenly by using an electric mixer. The wet clay was stored in a covered container for 24 hours. Certain amounts of glass fibers and cement were gradually added to the wet clay. The glass fibers were fully dispersed to ensure that the fibers were randomly and uniformly distributed in the soil to avoid potential damage to the surface due to bonding into clumps.

The mixture was transferred into molds $39.1 \mathrm{~mm}$ in diameter and $80 \mathrm{~mm}$ in height. The sample was compacted with the static compaction method specified in the Geotechnical Test Code for Railway Engineering (TB101022010) [40]. Each sample was extruded from the mold and wrapped with a plastic membrane (Figure 5). Then, it was cured in a standard curing box at a constant temperature of $(20 \pm 2)^{\circ} \mathrm{C}$ and relative humidity of more than $95 \%$ for 7 days.

\subsection{Test Program}

2.4.1. Consolidated Drained Triaxial Compression Test. A series of consolidated drained triaxial compression tests were conducted to investigate the effect of glass fiber inclusion on the mechanical behavior of cement-stabilized clay. An axial load was applied under an automatic straincontrolled apparatus (Figure 6). The saturated samples were consolidated with four different confining pressures (100, 200,300 , and $400 \mathrm{kPa}$ ). All consolidated drained triaxial tests were conducted using a strain rate of $0.5 \mathrm{~mm}$ per minute, and the tests were continued up to an axial strain of $20 \%$.

2.4.2. Scanning Electron Microscopy Test. The microstructure of the soil blocks selected from the damaged specimens (fiber content was $4 \%$, and cement content was $3 \%$ ) was assessed by SEM tests. Testing was conducted on $1 \mathrm{~cm} \times 1 \mathrm{~cm}$ cut pieces obtained from the specimens after the triaxial compression test.

\section{Results and Discussion}

\subsection{Stress-Strain Relationships and Volume Change Behavior}

3.1.1. Effect of the Fiber Content. Figures 7 and 8 present the typical deviatoric stress-axial strain behavior and volumetric strain-axial strain behavior of the specimens. The deviatoric stress at the axial strain of $20 \%$ is defined as the failure deviatoric stress in this study. 


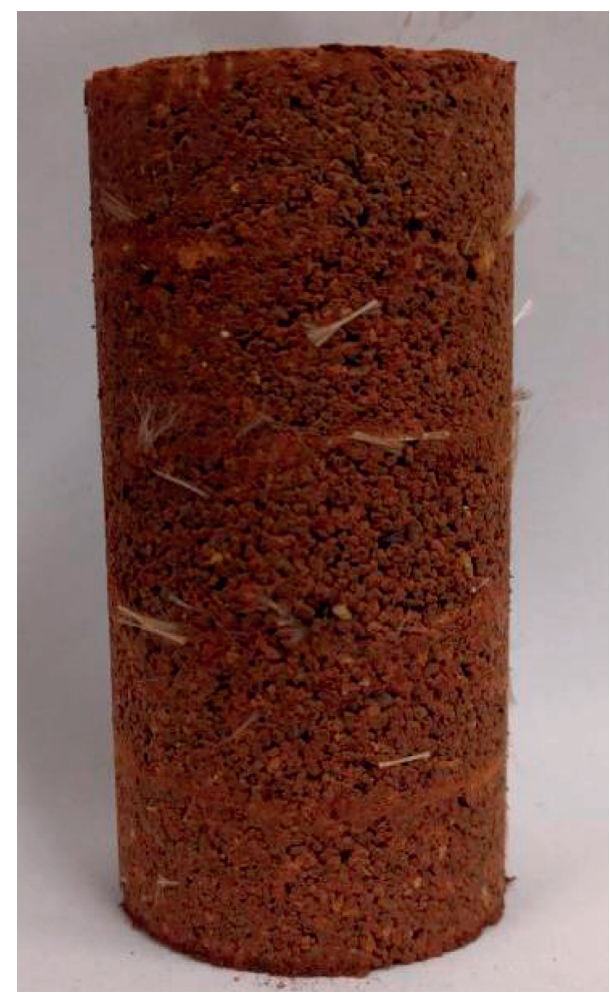

Figure 5: Photograph showing the specimens.

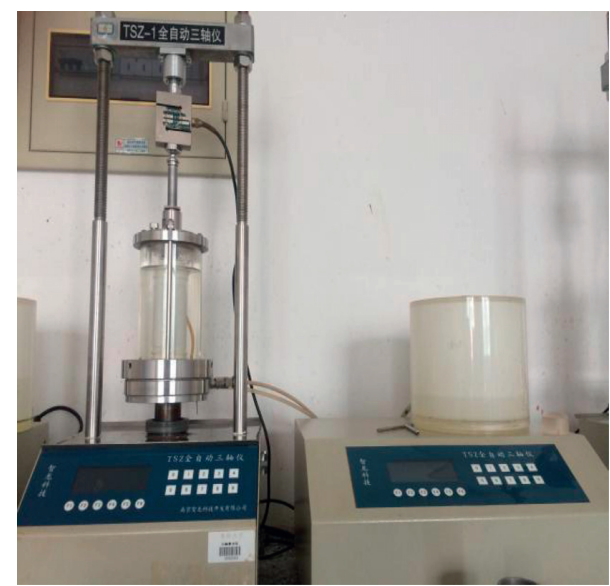

FIgURE 6: Photograph showing the triaxial apparatus.

Figure 7 shows that the stress-strain curves of the cement-stabilized clay reinforced with glass fibers are in a state of strain hardening at any fiber content. When the axial strain reaches $20 \%$, the deviatoric stress still exhibits an upward trend, and no substantial peak appears. When the axial strain is less than $2 \%$, the deviatoric stress of the cement-stabilized clay reinforced with glass fibers is approximately the same as that of the cement-stabilized clay without fibers. When the axial strain is greater than $2 \%$, the deviatoric stress of the cement-stabilized clay reinforced with glass fibers is greater than that of the cement-stabilized clay without fibers, and the deviatoric stress of the cementstabilized clay reinforced with glass fibers increases with the fiber content. The glass fibers require an initial deformation

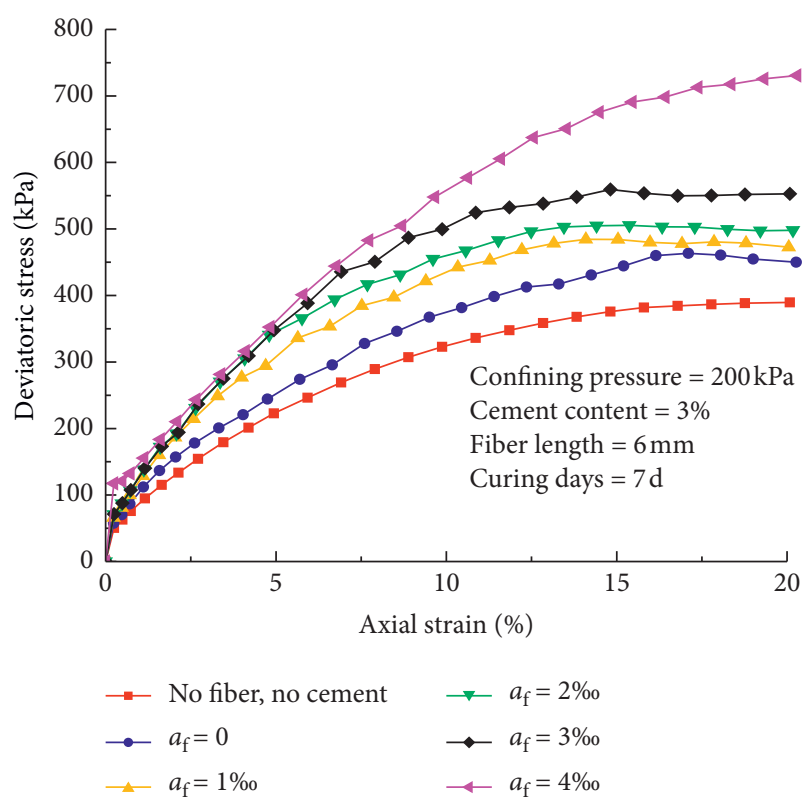

FIGURE 7: Effect of fiber content on deviatoric stress-axial strain behavior.

to mobilize its tensile strength [41]. The reinforcement effect of glass fibers is not substantial until the glass fiber reaches its initial deformation (the axial strain reaches $2 \%$ in this study).

The increase in the strength with increasing fiber content is attributed to the fiber tensile strength within the specimen and the friction force between the fibers and cement hydrates. A greater fiber content, corresponding to a greater number of fibers for a particular length, leads to a greater tensile strength and friction force contribution for the specimen. Furthermore, the internal tensile constraints generated by the fibers will have similar effects on the specimens under additional confining pressures [42], substantially increasing the strength and inhibiting the deformation of the soil. In addition, the randomly distributed glass fibers transfer the shear stress and strain to other regions, enhancing the overall performance of the specimen [43].

It can be observed from Figure 8 that the larger the fiber content is, the smaller the volumetric strain of the cementstabilized soil reinforced with glass fibers is. The addition of fibers can reduce the expansion deformation of the clay, so it has a good effect on suppressing the expansion of the clay. This is consistent with the triaxial experimental results presented by Masiri et al. [44].

To quantify the change in the strength of the specimens versus the fiber content, the strength enhancement is defined here as the increase in the failure deviatoric stress of the reinforced specimen compared to that of the corresponding unreinforced specimen, as shown in Figure 9. Figure 9 shows that the failure deviatoric stress and the strength enhancement of the specimens increase with the fiber content. The failure deviatoric stress of the cement-stabilized clay reinforced with $4 \%$ fibers is $55 \%$ higher than that of the unreinforced cement-stabilized clay. When the fiber content increases from $1 \%$ to $2 \%$, the change in strength 


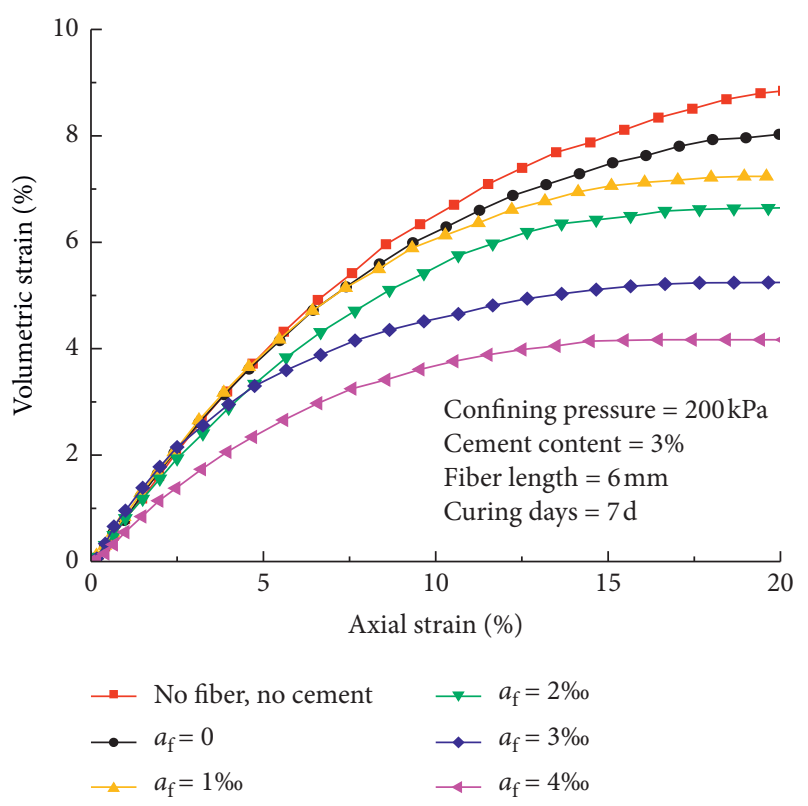

FIGURE 8: Effect of fiber content on volumetric strain-axial strain behavior.

enhancement is small, but when the fiber content increases from $3 \%$ to $4 \%$, the strength enhancement increases by three times, which shows that the growth rate of the failure deviatoric stress increases with the fiber content. The larger the fiber content is, the greater the strength increase is, and the more substantial the reinforcement effect is.

3.1.2. Effect of the Confining Pressure. Figure 10 presents the effect of the confining pressure on the deviatoric stress-axial strain behaviors of unreinforced and fiber-reinforced specimens. The deviatoric stresses of the cement-stabilized clay and the cement-stabilized clay reinforced with glass fibers increase with the confining pressure. The incorporation of fibers increases the initial stiffness of the specimen at any confining pressure. At a low confining pressure, the clay particles are relatively loose, and there are a large number of pores between the soil particles. As the confining pressure increases, the size of the pores gradually decreases, the soil gradually densifies to form a whole, and the bite force and friction between the glass fiber and the soil particles increase with the densification of the soil, causing the overall strength of the specimen to improve.

Figure 11 presents the typical volumetric strain-axial strain behavior of specimens reinforced with 3\%o fiber content and varying confining pressures. The volumetric strain of the cement-stabilized clay reinforced with glass fibers decreases with increasing confining pressure, which shows that the confining pressure can substantially restrain the expansion deformation of the soil. Similar expansion characteristics of reinforced sand under different confining pressures have been reported by Hamidi and Hooresfand [29]. A high confining pressure also restricts the stretching of the fibers and thereby restricts the effectiveness of the fibers in improving the strength with increasing confining pressure.

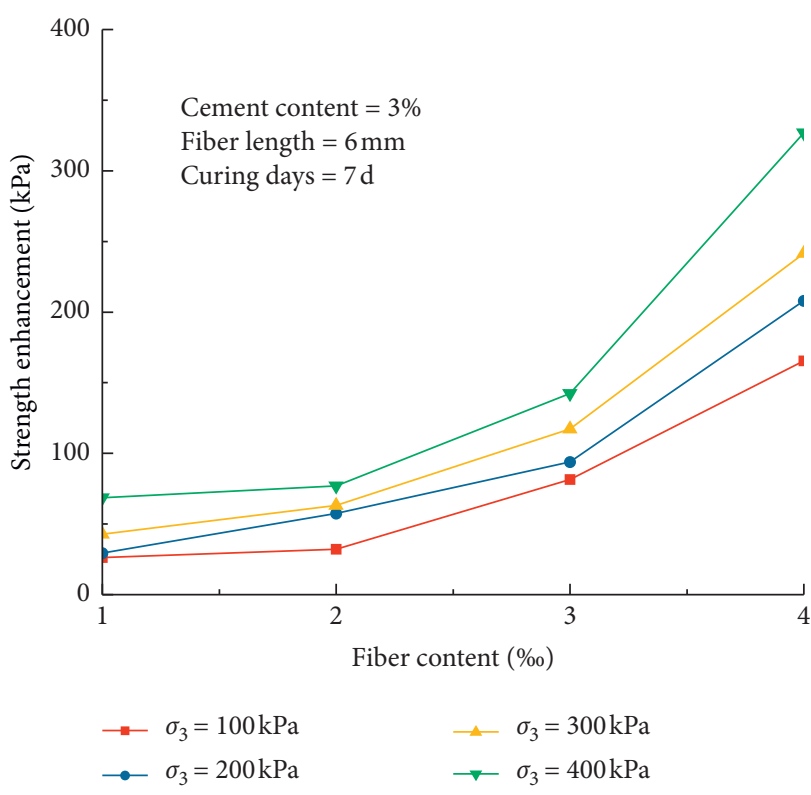

Figure 9: Strength enhancement under different fiber contents.

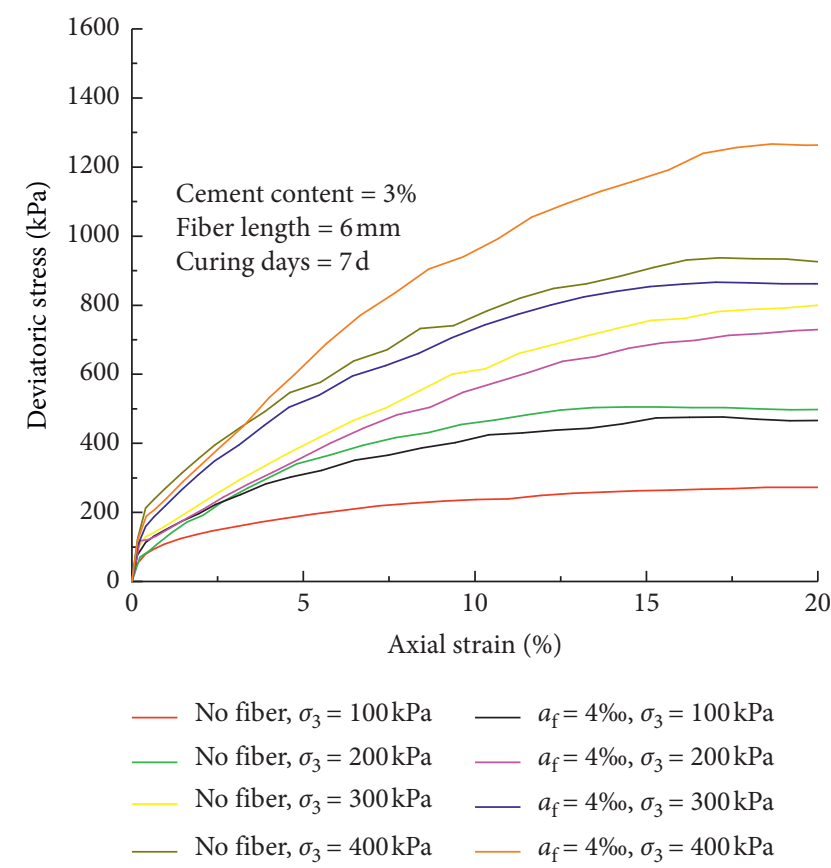

FIGURE 10: Effect of the confining pressure on the deviatoric stressaxial strain behavior.

Figure 12 shows the failure deviatoric stress of the specimen under different confining pressures. It can be seen from Figure 12 that the deviatoric stress at failure increases linearly with the confining pressure. When the confining pressure is $100 \mathrm{kPa}$, the difference between the failure deviatoric stress of the cement-modified soil and pure clay is small. However, with the increase in the confining pressure, the growth rate of the deviatoric stress at the failure of the cement-modified soil is higher than that of the pure clay, indicating that cement can effectively improve the strength 


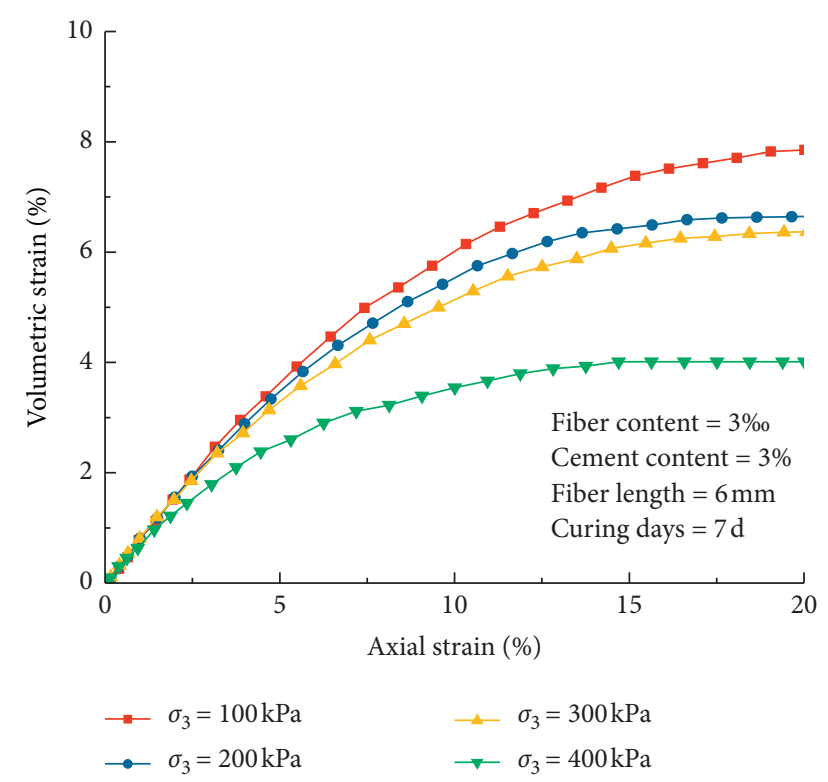

Figure 11: Effect of the confining pressure on the volumetric strain-axial strain behavior.

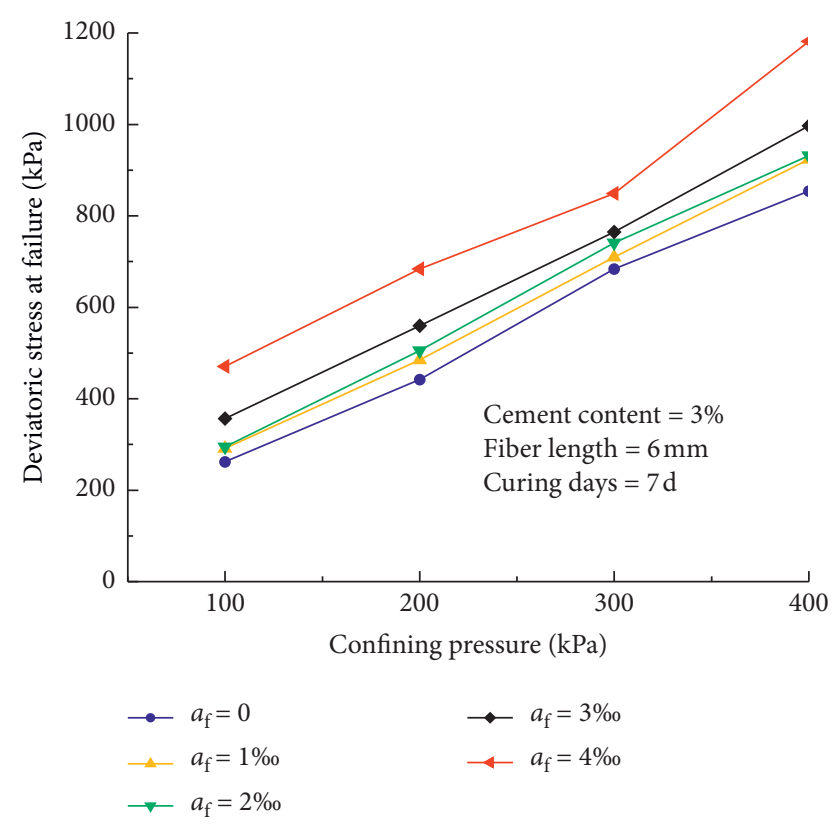

FIgURE 12: Deviatoric stress at failure under different confining pressures.

of the clay. The higher the confining pressure is, the more substantial the reinforcement effect is.

To quantify the change in the strength of the specimens versus the confining pressure, the strength ratio is defined here as the ratio of the failure deviatoric stress of the reinforced specimen to that of the corresponding unreinforced specimen, as shown in Figure 13. When the confining pressure is $100 \mathrm{kPa}$, the strength ratio is the largest, and then the strength ratio gradually decreases with increasing confining pressure. A greater fiber content will lead to a greater decrease in the strength ratio, which indicates that the

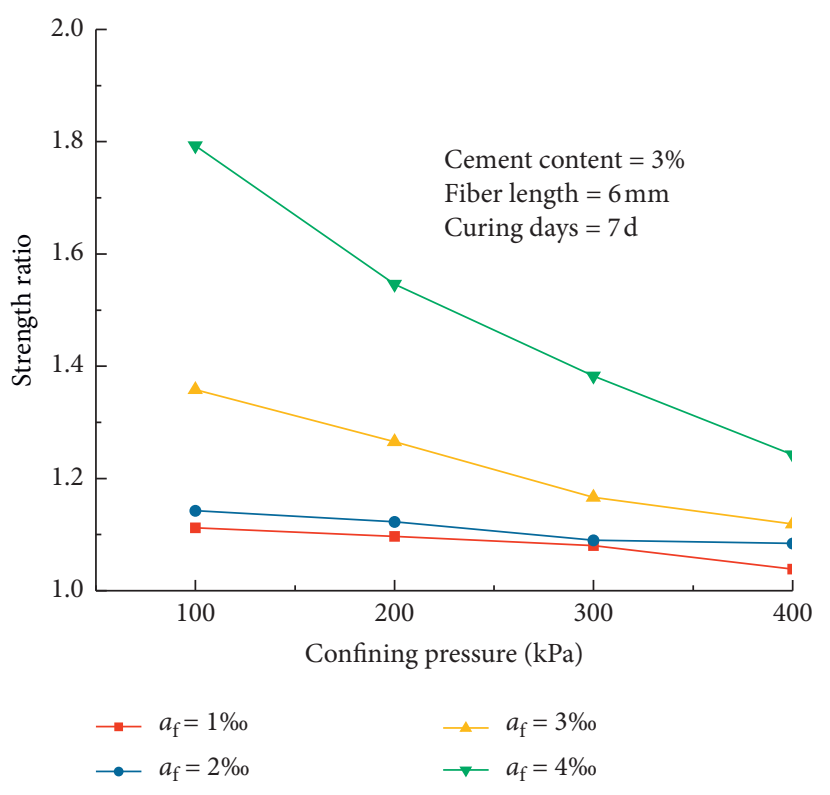

FIGURE 13: Strength ratio under different confining pressures.

reinforcement effect of the glass fibers is more substantial under a low confining pressure. Inside the soil mass, the randomly distributed fibers act as a spatial network, interlocking with soil particles to form a whole soil matrix. The soil matrix resists most of the applied loads at a relatively low strain level. With increasing axial strain, the lateral movement of the soil particles gradually mobilizes the tensile strength of the interlocked fibers, which will contribute to resisting the added shear force $[25,45]$. As the confining pressure increases, the lateral movement of the soil particles is minimized. Thus, the stretching of the fibers is also restricted, and the tensile strength of fibers themselves is not fully exerted, restricting the effectiveness of fibers for improving the strength [45].

The confining pressure has a double-sided effect on the deviatoric stress of the cement-stabilized clay reinforced with glass fibers $[46,47]$. On the one hand, after the soil is densified by a high confining pressure, the bite force and friction force between the glass fibers and soil particles gradually increase, causing the overall strength improvement of the specimen. On the other hand, the densified soil restricts the stretching of the fibers and thus limits the tensile strength of the glass fibers, which is not conducive to improving the reinforcement of the soil with glass fibers.

3.2. Failure Envelopes and Shear Strength Parameters. The shear strength envelope is a common tangent of multiple Mohr-Coulomb circles. Figure 14 shows the shear strength envelopes of different fiber contents. The shear strength parameters (cohesion and internal friction angle) are obtained by plotting the shear strength envelopes, as shown in Figure 15. The cohesion of the cement-stabilized clay reinforced with glass fibers substantially increases with the fiber content, while the friction angle is barely affected by 


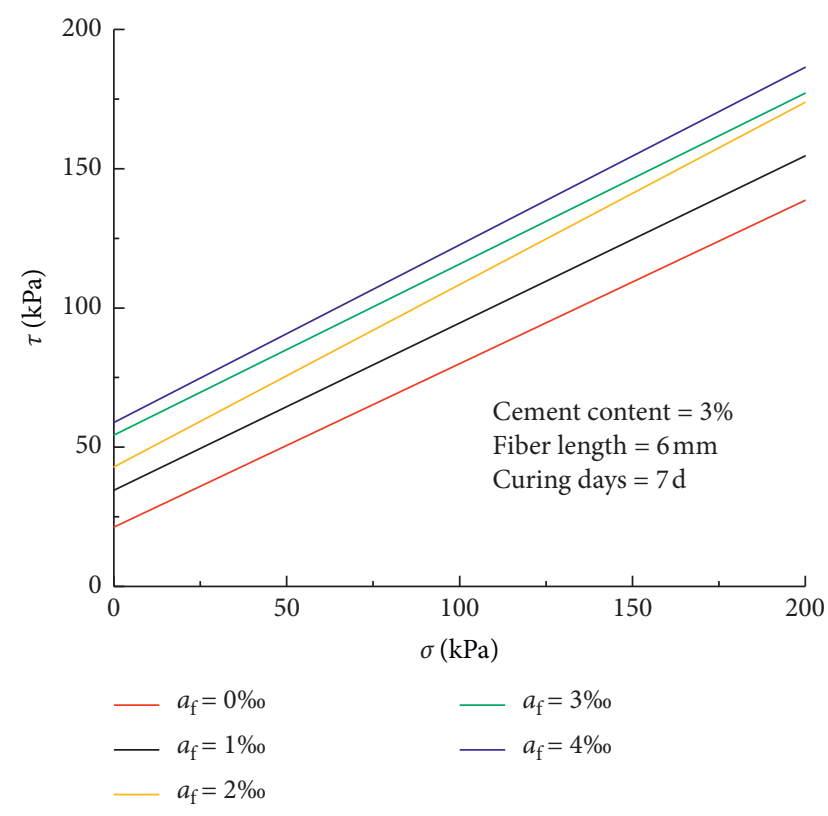

FIgURE 14: Mohr failure envelope.

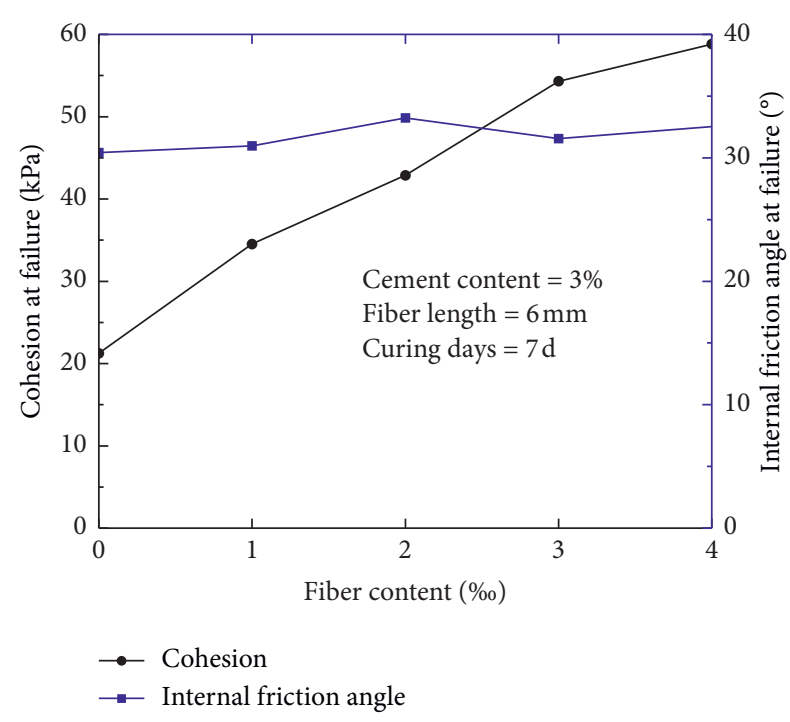

FIGURE 15: Shear strength parameters.

glass fiber inclusion. The cohesion of the cement-stabilized clay reinforced with glass fibers with $4 \%$ o fiber content is 2.8 times that of the cement-stabilized clay. This behavior is interesting because it contradicts the results reported by Consoli [33-35], who supported the idea that the fibers would reduce the cohesion of the specimen but substantially increase the friction angle of the specimen. The fiber surface is covered with a large number of cement hydrate crystals and soil particles. Interfacial forces such as the bite force and friction and interfacial plowing effects will be generated between the fiber and the soil particles, which make the fiber and soil form a fiber-soil column. When the specimen is under stress, it can disperse and transfer the applied loads and improve the cohesion of the cement-stabilized clay reinforced with glass fibers.
3.3. Energy Absorption. The energy absorption is the energy defined by the area under the stress-strain curve up to a reference strain level [48]. In triaxial testing, energy absorption represents the amount of energy required to induce deformation in the specimen. The energy absorption capacity is related to both the peak strength and the postpeak response. The effects of the fiber content on the energy absorption capacity of the specimens are evaluated considering a reference strain of 20\% (Figure 16).

Figure 17 shows the variation in the absorbed energy at an axial strain of $20 \%\left(\mathrm{ED}_{20 \%}\right)$ with the fiber content. $\mathrm{ED}_{20 \%}$ increases with the fiber content. This shows that glass fibers can effectively improve the strength and restrain the deformation of cement-stabilized clay. When the same deformation occurs, the energy absorption ability of the cementstabilized clay reinforced with glass fibers increases. The energy absorbed by the cement-stabilized clay is dissipated in the deformation of the soil matrix and cement hydrates. The energy absorbed by the cement-stabilized clay reinforced with glass fibers is mainly dissipated through the stretching of the glass fibers and friction along the fiber-soil interface.

The change in the ductility of soil is usually assessed in two ways, either from the variation in the postpeak stress loss or from the variation in the axial strain at failure $[49,50]$. Alternatively, the ductility of the cement-stabilized clay reinforced with glass fibers can be expressed by measuring the variation of the energy absorption along the stress-strain curve and expressing it in terms of normalized energy absorption [51]. $\mathrm{ED}_{20 \%}$ is normalized for different fiber contents as $\mathrm{ED} / \mathrm{ED}_{20 \%}$, and $\lambda=\mathrm{ED} / \mathrm{ED}_{20 \%}$ is defined. The variation in $\lambda$ with the axial strain at different fiber contents is shown in Figure 18.

In general, the greater the postpeak stress loss of the specimen is, the greater the normalized energy is and the lower the ductility of the specimen is. Therefore, at a given strain, the specimen with a lower value of normalized energy absorption (i.e., a lower value of $\lambda$ ) will display more ductile behavior and vice versa. The $\lambda$ values corresponding to $10 \%$ axial strain of clay, cement-stabilized clay, and cementstabilized clay reinforced with glass fibers with fiber contents of $2 \%$ and $4 \%$ are $0.41,0.43,0.40$, and 0.34 , respectively. The $\lambda$ value of the cement-stabilized clay is the largest, followed by that of clay, the $\lambda$ value of the cement-stabilized clay reinforced with glass fibers is the smallest, and the $\lambda$ value of the cement-stabilized clay reinforced with glass fibers decreases with the fiber content. This shows that the glass fibers can substantially improve the ductility of the soil. When local cracks appear in a specimen, some fibers across these cracks are responsible for the tension in the soil by fiber-soil friction, which effectively impedes the further development of cracks and improves the ductility of the cement-stabilized clay and accordingly changes the failure mode of the cement-stabilized clay [52].

3.4. Interface Phenomenon and Micromechanism. The microstructures of glass fibers and cement-stabilized clay reinforced with glass fibers were observed and analyzed by scanning electron microscopy, as shown in Figure 19. 


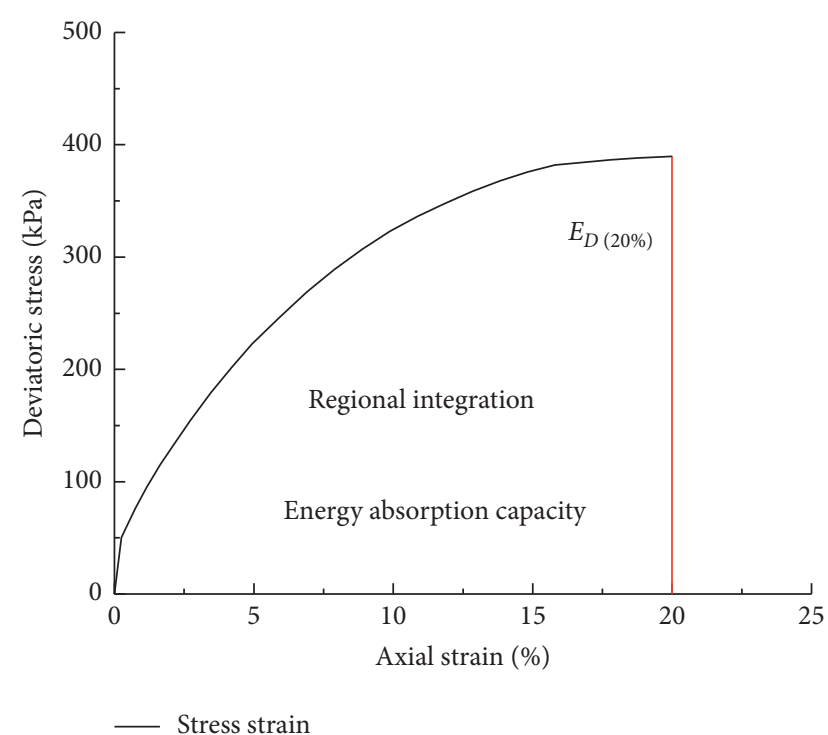

Figure 16: Energy absorption capacity calculation.

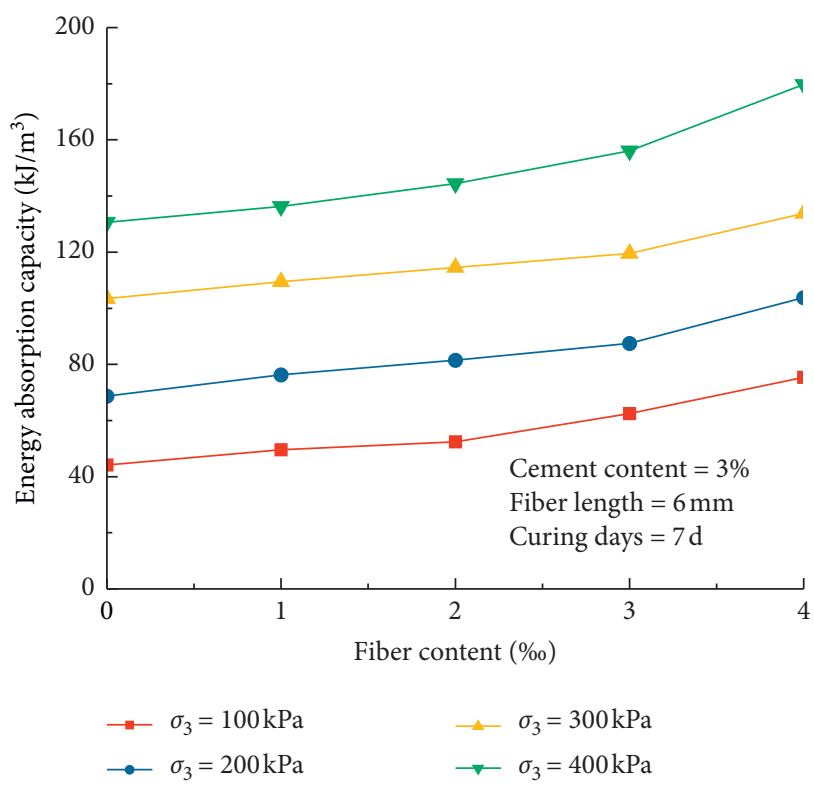

FIGURE 17: Energy absorption capacity under different fiber contents.

Figure 19(a) shows that the single glass fiber has a diameter of $18.36 \mu \mathrm{m}$, and the fiber surface is smooth. From Figure 19(b), it can be seen that the surface of the glass fiber is covered with cement hydrate crystals and soil particles, which increases the bonding force between the glass fiber and cement hydrates, substantially improves the fiber-soil interface bonding characteristics, and increases the bite force and friction between the fiber and soil particles [53]. Therefore, the failure deviatoric stress and cohesion of cement-stabilized clay have been greatly improved by glass fibers. In addition, the cement hydrate crystals are much harder than the glass fibers, and, thus, the cement hydrate crystals easily penetrate into the fiber and cause interfacial plowing effects during shearing. Shooter and Tabor [54]

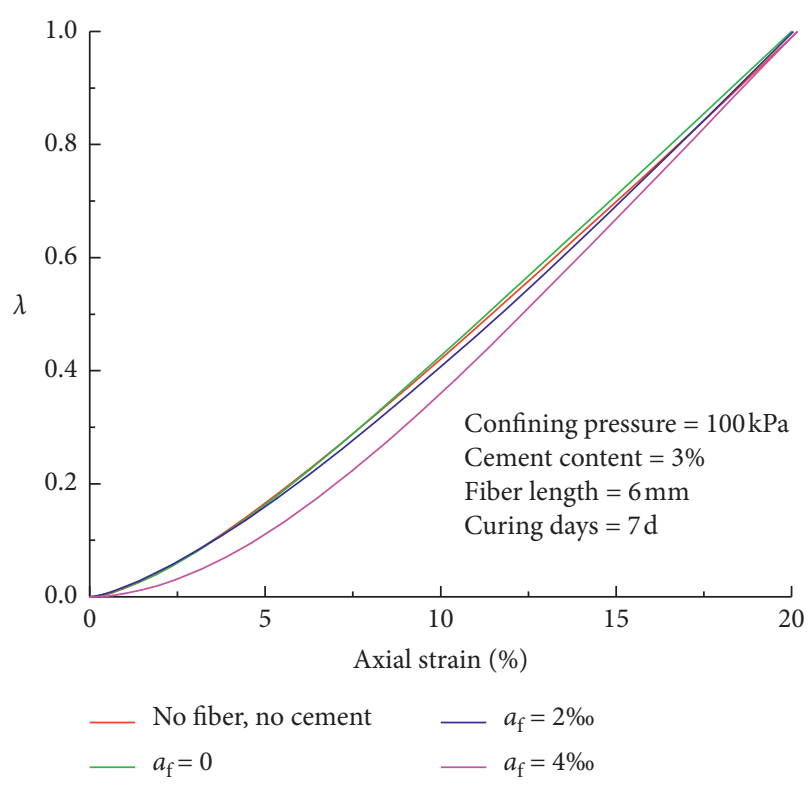

FIGURE 18: Variation in the normalized absorbed energy with axial strain for different fiber contents.

stated that the plowing effect during shearing results in a higher interfacial friction than that of adhesive sliding alone. The cement hydrates distributed between the clay particles bind the soil particles together and make the soil matrix denser [55], thus greatly restricting the rearrangement of the soil particles at the fiber-soil interface and increasing the effective contact area of the fiber-soil interface, and then the displacement and deformation of soil particles are constrained. Glass fibers can significantly increase the failure strain of the soil.

As seen from Figure 19(c), the high strength of the glass fiber itself makes it difficult for the fiber to be broken. When the pulling force overcomes the fiber-soil interface force [23], the glass fiber will be pulled out as a whole, and a hole is left in the cement stabilized clay, as shown in Figure 19(d), which is similar to anchor rod pulled out from grout. Therefore, more energy needs to be absorbed by samples to pull the fibers out of the soil; and the larger the fiber content is, the more energy is needed to pull out the fiber.

The fibers, soil particles, and cement hydrates interact with and restrict each other. Therefore, the interaction mechanism between a fiber, the soil particles, and the cement hydrates is complicated $[47,56,57]$, as shown in Figure 20.

The interfacial force of a single fiber can be extended to the entire fiber network, and the three-dimensional network structure formed by randomly distributed discrete glass fibers (Figure 19) realizes the interlinkage of the soil particles under the interfacial force, which contributes to restraining soil dilation [47]. When the cement-stabilized clay reinforced with glass fibers is under stress, the cement hydrates developed between the soil particles are the first to withstand the external loads due to their high tensile strength. Once the external loads exceed the tensile strength, the cement hydrate crystals break, and the glass fibers begin to function. 


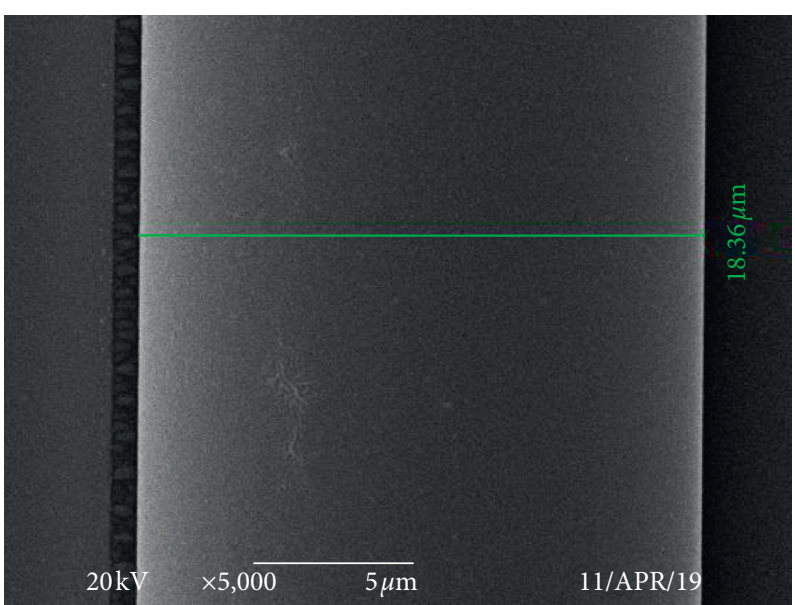

(a)

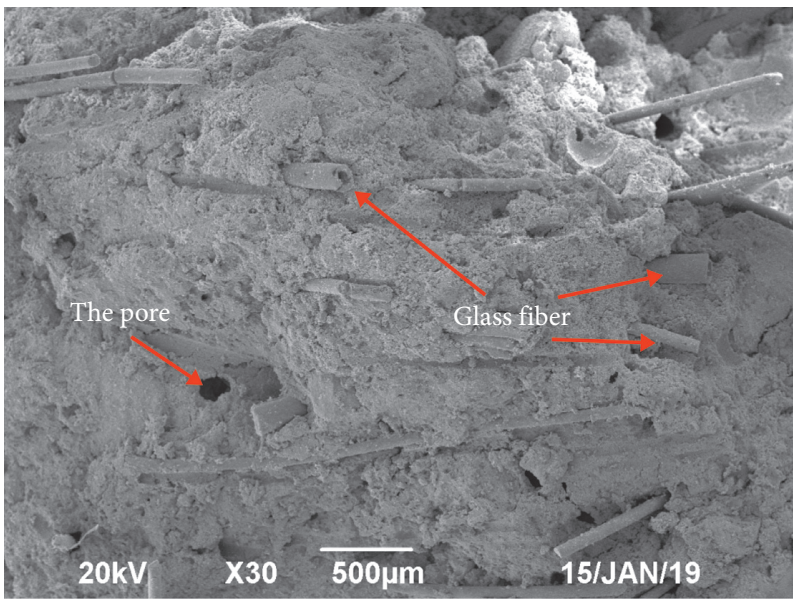

(c)

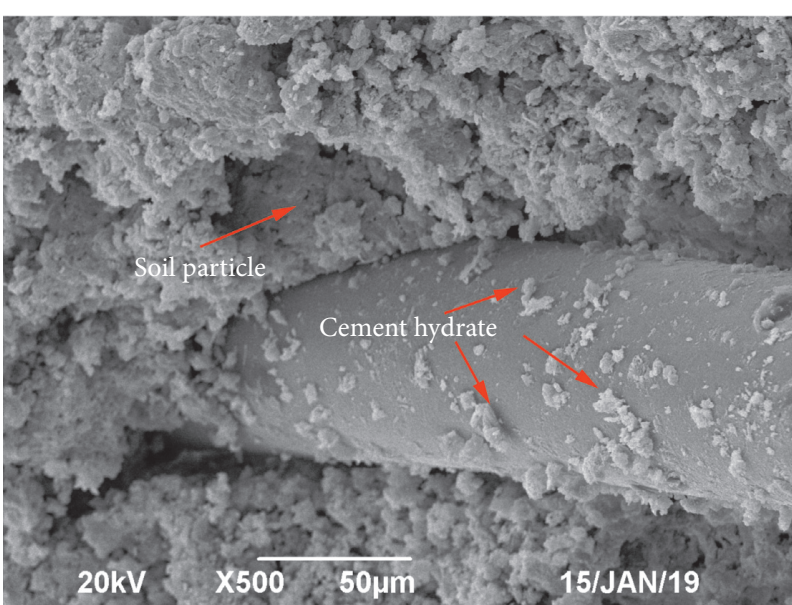

(b)

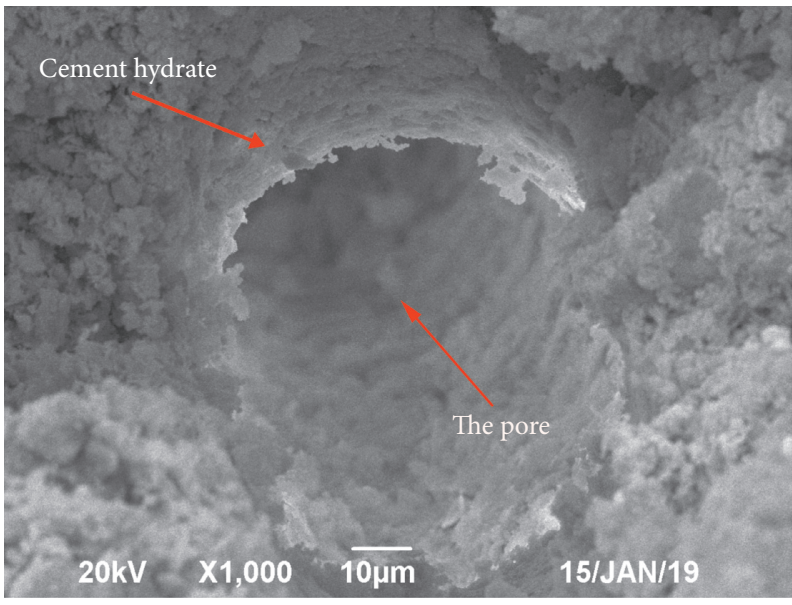

(d)

Figure 19: Cement-stabilized clay reinforced with glass fibers. (a) Glass fiber surface. (b) Cement hydrates and soil particles on the fiber surface. (c) Glass fibers embedded in soil. (d) The pore after the fiber was pulled out.

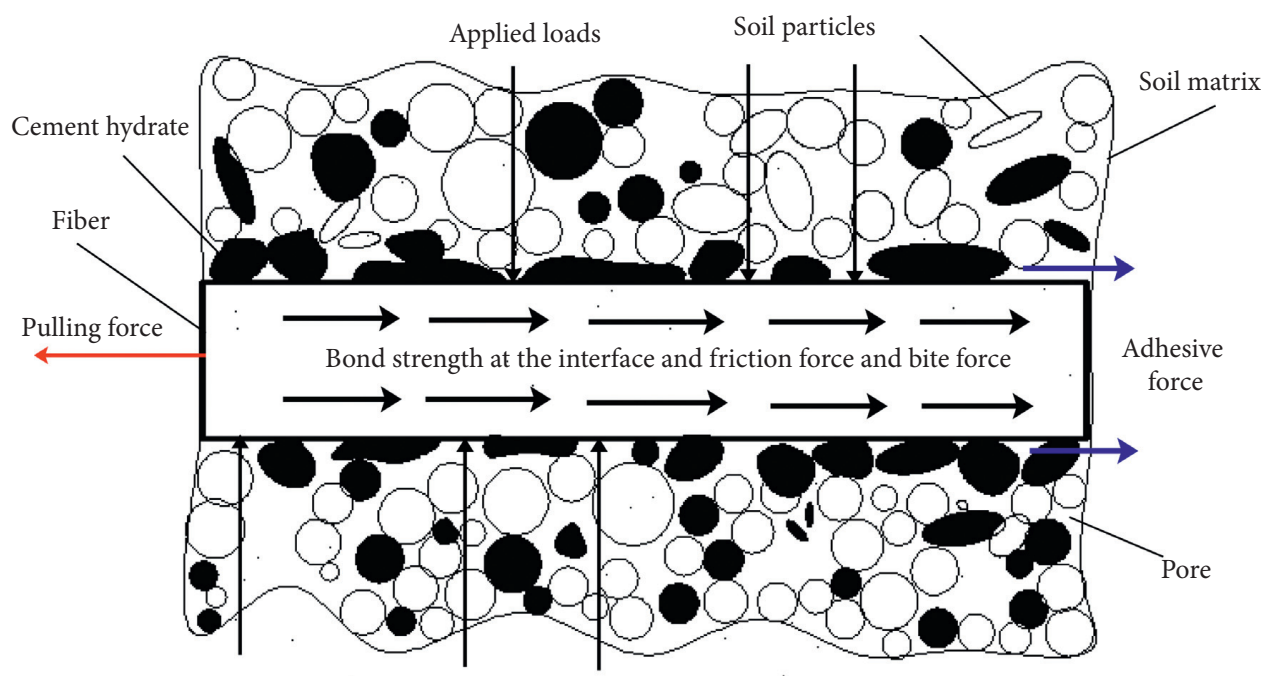

Figure 20: Interfacial force. 
Due to the interfacial force and the high tensile strength of the glass fibers themselves, the fibers are not easily broken. After a fiber is pulled out, the specimen breaks, and the stress reaches a peak value.

\section{Conclusion}

This study performs a series of consolidated drained triaxial compression tests to investigate the effects of glass fibers on the strength and deformation characteristics of cementstabilized clay reinforced with glass fibers. The main conclusions from the test results can be summarized as follows:

(1) When the axial strain is less than $2 \%$, the deviatoric stress of the cement-stabilized clay reinforced with glass fibers is barely affected by glass fiber inclusion; however, when the axial strain is greater than $2 \%$, the effect of the fiber reinforcement is substantial, and the deviatoric stress of the cement-stabilized clay reinforced with glass fibers increases with the fiber content.

(2) The failure deviatoric stress of the cement-stabilized clay reinforced with glass fibers increases with the fiber content and confining pressure. However, the strength ratio of the cement-stabilized clay reinforced with glass fibers is found to be higher under a low confining pressure. When the fiber content is $4 \%$ and the confining pressure increases from $100 \mathrm{kPa}$ to $400 \mathrm{kPa}$, the volumetric strain decreases by $31 \%$.

(3) The glass fibers and confining pressure can effectively inhibit the dilatancy of cement-stabilized clay reinforced with glass fibers. The dilation of the cementstabilized clay reinforced with glass fiber decreases with the fiber content and confining pressure. When the confining pressure is $200 \mathrm{kPa}$, the residual expansion values of the reinforced specimens with fiber contents of $4 \%$ and $1 \%$ are reduced by $10 \%$ and $48 \%$ compared to the unreinforced specimens.

(4) The increase in the shear strength of the cementstabilized clay reinforced with glass fibers is mainly due to the increase in cohesion, which substantially increases with the fiber content. The friction angle is barely affected by glass fiber inclusion. The cohesion of the reinforced specimens with $4 \%$ o fiber content is 2.8 times that of the unreinforced specimens.

(5) The inclusion of glass fibers increases the ductility and the energy absorption capacity of the cementstabilized clay reinforced with glass fibers. The energy absorption capacity and ductility of the cementstabilized clay reinforced with glass fiber increase with the fiber content. When the confining pressure is $200 \mathrm{kPa}$, the energy absorption capacities of the reinforced specimens with fiber contents of $1 \%$ and $4 \%$ are 1.1 times and 1.5 times those of the unreinforced specimens, respectively.

(6) The surface of the glass fiber is covered with cement hydrate crystals and soil particles which improves the fiber-soil interface bonding characteristics and increases the bite force and friction between the fiber and soil particles. The fiber is similar to an anchor rod in the soil, which enhances the strength of the soil. The discretely distributed glass fibers form a three-dimensional network in the soil, which contributes to restraining soil dilation.

\section{Data Availability}

The data used to support the findings of this study are available from the corresponding author upon request.

\section{Conflicts of Interest}

The authors declare that they have no conflicts of interest.

\section{Acknowledgments}

This work was supported by the National Natural Science Foundation of China (nos. 51878665 and 51978672) and the Natural Science Foundation of Hunan Province, China (no. 2020JJ5748).

\section{References}

[1] Ministry of Construction, TB 10621-2009, Code for Design of High Speed Railway, Ministry of Construction, Beijing, China, 2009.

[2] G. Zhao, W. She, G. Yang et al., "Mechanism of cement on the performance of cement stabilized aggregate for high speed railway roadbed," Construction and Building Materials, vol. 144, pp. 347-356, 2017.

[3] T.-l. Wang, H.-h. Wang, H.-f. Song, Z.-r. Yue, and Z.-h. Guo, "Effects of cement content and grain-size composition on engineering properties of high-speed-railway macadam subgrade," Cold Regions Science and Technology, vol. 145, pp. 21-31, 2018.

[4] Y. Cai, L. Xu, W. Liu et al., "Field Test Study on the dynamic response of the cement-improved expansive soil subgrade of a heavy-haul railway," Soil Dynamics and Earthquake Engineering, vol. 128, no. 10, pp. 58-78, 2020.

[5] H. Yan, G. Zhao, D. Cai et al., "Research on anti-frost heaving structure of permeable subgrade bed on high speed railway," Railway Engineering, vol. 5, pp. 98-102, 2015.

[6] T.-l. Wang, H.-f. Song, Z.-r. Yue, T.-f. Hu, T.-c. Sun, and H.-b. Zhang, "Freeze-thaw durability of cement-stabilized macadam subgrade and its compaction quality index," Cold Regions Science and Technology, vol. 160, pp. 13-20, 2019.

[7] X. F. Yang, "Design research on subgrade anti-frost for highspeed railway in high latitude and severe cold region," Railway Standard Design, vol. 58, no. 8, pp. 6-11, 2014.

[8] J. Teng, X. Zhang, S. Zhang, C. Zhao, and D. Sheng, "An analytical model for evaporation from unsaturated soil," Computers and Geotechnics, vol. 108, pp. 107-116, 2019.

[9] J. Teng, F. Shan, Z. He, S. Zhang, G. Zhao, and D. Sheng, "Experimental study of ice accumulation in unsaturated clean sand," Géotechnique, vol. 69, no. 3, pp. 251-259, 2019.

[10] J. Teng, J. Liu, S. Zhang, and D. Sheng, "Modelling frost heave in unsaturated coarse-grained soils," Acta Geotechnica, vol. 15, no. 11, pp. 3307-3320, 2020.

[11] Z. Lin, F. Niu, X. Li et al., "Characteristics and controlling factors of frost heave in high-speed railway subgrade, 
Northwest China," Cold Regions Science and Technology, vol. 153, pp. 33-44, 2018.

[12] J. J. Li and R. W. Liang, "Experimental study on compressive strength and deformation modulus of cement soil," Rock and Soil Mechanics, vol. 30, no. 2, pp. 473-477, 2009, in Chinese.

[13] F. Chen, "Strength and deformation characteristics of basalt fiber cement-soil at early age," Journal of Shenzhen University Science and Engineering, vol. 34, no. 6, pp. 611-617, 2017, in Chinese.

[14] M. S. Chauhan, S. Mittal, and B. Mohanty, "Performance evaluation of silty sand subgrade reinforced with fly ash and fibre," Geotextiles and Geomembranes, vol. 26, no. 5, pp. 429-435, 2008.

[15] C. Tang, B. Shi, W. Gao, F. Chen, and Y. Cai, "Strength and mechanical behavior of short polypropylene fiber reinforced and cement stabilized clayey soil," Geotextiles and Geomembranes, vol. 25, no. 3, pp. 194-202, 2007.

[16] G. M. Latha and V. S. Murthy, "Effects of reinforcement form on the behavior of geosynthetic reinforced sand," Geotextiles and Geomembranes, vol. 25, no. 1, pp. 23-32, 2007.

[17] N. C. Consoli, A. Viana da Fonseca, R. C. Cruz, and K. S. Heineck, "Fundamental parameters for the stiffness and strength control of artificially cemented sand," Journal of Geotechnical and Geoenvironmental Engineering, vol. 135, no. 9, pp. 1347-1353, 2009.

[18] R. L. Michalowski and J. Čermák, "Triaxial compression of sand reinforced with fibers," Journal of Geotechnical and Geoenvironmental Engineering, vol. 129, no. 2, pp. 125-136, 2003.

[19] N. C. Consoli, M. A. Arcari Bassani, and L. Festugato, "Effect of fiber-reinforcement on the strength of cemented soils," Geotextiles and Geomembranes, vol. 28, no. 4, pp. 344-351, 2010.

[20] X. Chen, X. Shi, J. Zhou, Q. Chen, E. Li, and X. Du, "Compressive behavior and microstructural properties of tailings polypropylene fibre-reinforced cemented paste backfill," Construction and Building Materials, vol. 190, no. 11, pp. 211-221, 2018.

[21] A. Boz, A. Sezer, T. Özdemir, G. E. Hizal, and Ö. A. Dolmac1, "Mechanical properties of lime-treated clay reinforced with different types of randomly distributed fibers," Arabian Journal of Geosciences, vol. 11, no. 6, p. 122, 2018.

[22] J. Lovisa, S. K. Shukla, and N. Sivakugan, "Shear strength of randomly distributed moist fibre-reinforced sand," Geosynthetics International, vol. 17, no. 2, pp. 100-106, 2010.

[23] N. Cristelo, V. M. C. F. Cunha, M. Dias, A. T. Gomes, T. Miranda, and N. Araújo, "Influence of discrete fibre reinforcement on the uniaxial compression response and seismic wave velocity of a cement-stabilised sandy-clay," Geotextiles and Geomembranes, vol. 43, no. 1, pp. 1-13, 2015.

[24] O. Plé and T. N. H. Lê, "Effect of polypropylene fiber-reinforcement on the mechanical behavior of silty clay," Geotextiles and Geomembranes, vol. 32, pp. 111-116, 2012.

[25] C. A. Anagnostopoulos, D. Tzetzis, and K. Berketis, "Shear strength behaviour of polypropylene fibre reinforced cohesive soils," Geomechanics and Geoengineering, vol. 9, no. 3, pp. 241-251, 2014.

[26] L. Festugato, E. Menger, F. Benezra, E. A. Kipper, and N. C. Consoli, "Fibre-reinforced cemented soils compressive and tensile strength assessment as a function of filament length," Geotextiles and Geomembranes, vol. 45, no. 1, pp. 77-82, 2017.

[27] N. C. Consoli, D. Foppa, L. Festugato, and K. S. Heineck, "Key parameters for strength control of artificially cemented soils,"
Journal of Geotechnical and Geoenvironmental Engineering, vol. 133, no. 2, pp. 197-205, 2007.

[28] N. C. Consoli, M. A. Vendruscolo, A. Fonini, and F. D. Rosa, "Fiber reinforcement effects on sand considering a wide cementation range," Geotextiles and Geomembranes, vol. 27, no. 3, pp. 196-203, 2009.

[29] A. Hamidi and M. Hooresfand, "Effect of fiber reinforcement on triaxial shear behavior of cement treated sand," Geotextiles and Geomembranes, vol. 36, pp. 1-9, 2013.

[30] D. Mujah, H. Hazarika, F. Ahmad et al., "Development of ground improving geomaterial using recycled glass fibers," in Proceedings of the JSCE Annual Meeting and Conference, Ehime University, Matsuyama, Japan, September 2011.

[31] D. Mujah, F. Ahmad, H. Hazarika, and A. Safari, "Evaluation of the mechanical properties of recycled glass fibers-derived three dimensional geomaterial for ground improvement," Journal of Cleaner Production, vol. 52, pp. 495-503, 2013.

[32] F. Ahmad, D. Mujah, H. Hazarika, and A. Safari, "Assessing the potential reuse of recycled glass fibre in problematic soil applications," Journal of Cleaner Production, vol. 35, pp. 102-107, 2012.

[33] N. C. Consoli, P. D. M. Prietto, and L. A. Ulbrich, "Influence of fiber and cement addition on behavior of sandy soil," Journal of Geotechnical and Geoenvironmental Engineering, vol. 124, no. 12, pp. 1211-1214, 1998.

[34] N. C. Consoli, J. P. Montardo, P. D. M. Prietto, and G. S. Pasa, "Engineering behavior of a sand reinforced with plastic waste," Journal of Geotechnical and Geoenvironmental Engineering, vol. 128, no. 6, pp. 462-472, 2002.

[35] N. C. Consoli, J. P. Montardo, M. Donato, and P. D. Prietto, "Effect of material properties on the behaviour of sand-cement-fibre composites," Proceedings of the Institution of Civil Engineers-Ground Improvement, vol. 8, no. 2, pp. 77-90, 2004.

[36] S. S. Kutanaei and A. J. Choobbasti, "Triaxial behavior of fiberreinforced cemented sand," Journal of Adhesion Science and Technology, vol. 30, no. 6, pp. 579-593, 2016.

[37] R. Fu, B. A. Baudet, B. N. Madhusudhan, and M. R. Coop, “A comparison of the performances of polypropylene and rubber fibers in completely decomposed granite," Geotextiles and Geomembranes, vol. 46, no. 1, pp. 22-28, 2018.

[38] E. Ibraim and S. Fourmont, "Behavior of sand reinforced with fibers, soil stress-strain behavior: measurement, modeling and analysis," in Proceedings of the Geotechnical Symposium in Roma, pp. 806-818, Rome, Italy, March 2006.

[39] A. Diambra, E. Ibraim, D. Muir Wood, and A. R. Russell, "Fibre reinforced sands: experiments and modelling," Geotextiles and Geomembranes, vol. 28, no. 3, pp. 238-250, 2010.

[40] Ministry of Construction, TB10102-2010.Code for Soil Test of Railway Engineering, Ministry of Construction, Beijing, China, 2010.

[41] J. G. Zornberg, "Discrete framework for limit equilibrium analysis of fibre-reinforced soil," Géotechnique, vol. 52, no. 8, pp. 593-604, 2002.

[42] N. C. Consoli, M. D. T. Casagrande, A. Thomé, F. Dalla Rosa, and M. Fahey, "Effect of relative density on plate loading tests on fibre-reinforced sand," Géotechnique, vol. 59, no. 5, pp. 471-476, 2009.

[43] Z. H. Özkul and G. Baykal, "Shear behavior of coMPacted rubber fiber-clay composite in drained and undrained loading," Journal of Geotechnical and Geoenvironmental Engineering, vol. 133, no. 7, pp. 767-781, 2007.

[44] M. S. Mashiri, J. S. Vinod, M. N. Sheikh, and H.-H. Tsang, "Shear strength and dilatancy behaviour of sand-tyre chip mixtures," Soils and Foundations, vol. 55, no. 3, pp. 517-528, 2015. 
[45] H. J. Pincus, M. H. Maher, and Y. C. Ho, "Behavior of fiberreinforced cemented sand under static and cyclic loads," Geotechnical Testing Journal, vol. 16, no. 3, 1993.

[46] S. Goodarzi and H. Shahnazari, "Strength enhancement of geotextile-reinforced carbonate sand," Geotextiles and Geomembranes, vol. 47, pp. 128-139, 2019.

[47] L. Gao, G. H. Hu, N. Xu et al., "Experimental study on unconfined compressive strength of basalt fiber reinforced clay soil," Advances in Materials Science and Engineering, vol. 2015, Article ID 561293, 8 pages, 2015.

[48] ASTM International, ASTM C1018. 1997. Standard Test Method for Flexural Toughness and First Crack Strength of Fiber-Reinforced Concrete (Using Beam with Third Point Loading), ASTM International, West Conshohocken, PA, USA, 1997.

[49] F. Ahmad, F. Bateni, and M. Azmi, "Performance evaluation of silty sand reinforced with fibres," Geotextiles and Geomembranes, vol. 28, no. 1, pp. 93-99, 2010.

[50] S. Dhar and M. Hussain, "The strength behaviour of limestabilised plastic fibre-reinforced clayey soil," Road Materials and Pavement Design, vol. 20, no. 8, pp. 1757-1778, 2019.

[51] Y. Amini and A. Hamidi, "Triaxial shear behavior of a cementtreated sand-gravel mixture," Journal of Rock Mechanics and Geotechnical Engineering, vol. 6, no. 5, pp. 455-465, 2014.

[52] Y. Cai, B. Shi, C. W. W. Ng, and C.-s. Tang, "Effect of polypropylene fibre and lime admixture on engineering properties of clayey soil," Engineering Geology, vol. 87, no. 3-4, pp. 230-240, 2006.

[53] B. Zheng, D. Zhang, W. Liu, Y. Yang, and H. Yang, "Use of basalt fiber-reinforced tailings for improving the stability of tailings dam," Materials, vol. 12, no. 8, p. 1306, 2019.

[54] K. V. Shooter and D. Tabor, "The frictional properties of plastics," Proceedings Of the Physical Society. Section B, vol. 65, no. 9, pp. 661-671, 1952.

[55] C.-S. Tang, B. Shi, and L.-Z. Zhao, "Interfacial shear strength of fiber reinforced soil," Geotextiles and Geomembranes, vol. 28 , no. 1, pp. 54-62, 2010.

[56] D. X. Wang, H. W. Wang, S. Larsson et al., "Effect of basalt fiber inclusion on the mechanical properties and microstructure of cement-solidified kaolinite," Construction and Building Materials, vol. 241, Article ID 118085, 2020.

[57] Z. Cao, Q. Ma, and H. Wang, "Effect of basalt fiber addition on static-dynamic mechanical behaviors and microstructure of stabilized soil compositing cement and fly Ash," Advances in Civil Engineering, vol. 2019, Article ID 8214534, 20 pages, 2019. 